\title{
Torakolomber ve lomber omurga kırıklarına biyomekanik yaklaşım
}

\section{Fractures of thoracolumbar and lumbar spine: the biomechanical approach}

\author{
Mustafa Erkan İnanmaz ${ }^{1}$, Alper Kurtoğlu² \\ 'Sakarya Üniversitesi Tıp Fakültesi, Ortopedi ve Travmatoloji Anabilim Dalı, Sakarya \\ ${ }^{2}$ S.B. Sakarya Eğitim ve Araştırma Hastanesi, Ortopedi ve Travmatoloji Bölümü, Sakarya
}

\begin{abstract}
Mekanik ilkelerin canlı organizmalara uygulanması olan biyomekanik, omurgayı oluşturan kemik ve yumuşak doku bileşenlerinin tek tek ve birlikte spinal stabiliteyi sağlamak için nasıl katkıda bulunduğunu aynı zamanda travma, tümör ve dejeneratif bozuklukların destabilize edici etkilerini nasıl gösterdiklerini anlamamıza yardımcı olur. Omurga stabilitesi nöral yapılarını korunması ve omurganın erken mekanik bozulmasını önlemek için temel gereksinimdir. Literatürde spinal stabilitenin birçok biyomekanik ve klinik tanımı yer almaktadır ancak üzerinde uzlaşı sağlanmış bir tanımı yoktur. Kemik, disk ve bağlar yapısal rollerinin yanında mekanoreseptörleri aracılığıyla transdüserler olarak hareket ederek stabiliteye katkıda bulunur. Mekanoreseptörler kas tonusu, hareket ve refleksleri koordine eden merkezi sinir sistemine propriyoseptif iletiler gönderir. Dolayısıyla herhangi bir omurga yapısının hasarlanması, farklı derecelerde bir instabilitenin ortaya çıkmasına neden olur. Torakal ve lomber omurga kırıkları yaşam kalitesinde ani bir değişikliğe neden olurken, ağrı ve fonksiyonel kayıplarla birlikte kronik komplikasyonlara da yol açar. Omurga yaralanmaları, farklı travmatik duyarlılığa ve iyileşme potansiyeline sahip yumuşak dokulardan ve kemik yapılardan oluşan karmaşık bir yapıyı etkiler. Bu karmaşıklık, sınıflandırmayı, instabiliteyi ve tedavi sonuçlarını değerlendirmeyi zorlaştırır. Bununla birlikte, dejeneratif instabilitenin aksine, travmatik instabilite, görüntüleme bulguları ve klinik semptomlar arasında daha doğrudan olan bir ilişki mevcuttur. Omurga kırıklarında meydana gelen instabilitenin tanımlanması için araştırmalar devam etmektedir. Kırıklar geleneksel olarak stabil ve instabil olarak ayrılsa da, tüm omurga bileşenleri stabiliteye katkıda bulunur. Herhangi bir spinal yapının zarar görmesi, bir miktar instabiliteye neden olur; dolayısıyla instabilite, "ya hep ya da hiç" yaklaşımıyla değerlendirilebilecek bir olgu değildir.
\end{abstract}

Anahtar sözcükler: torakolomber omurga; biyomekanik; instabilite
Biomechanics, the application of mechanical principles to living organisms, helps us to understand how all the bony and soft spinal components contribute individually and together to ensure spinal stability, and how traumas, tumours and degenerative disorders exert destabilizing effects. Spine stability is the basic requirement to protect nervous structures and prevent the early mechanical deterioration of spinal components. The literature reports a number of biomechanical and clinical definitions of spinal stability, but a consensus definition is lacking. Bones, disks and ligaments contribute by playing a structural role and by acting as transducers through their mechanoreceptors. Mechanoreceptors send proprioceptive impulses to the central nervous system which coordinates muscle tone, movement and reflexes. Therefore, damage to any spinal structure gives rise to some degree of instability. Thoracic and lumbar fractures often result in an abrupt change in the patient's quality of life, and with persistent pain, can result in functional loss leading to chronic complications over time. Spinal traumas affect a complex structure composed of soft and bony components having different traumatic susceptibility and healing potential. This complexity hampers the classification of traumas, the assessment of instability, and treatment outcomes. However, unlike degenerative instability, the relationship between imaging findings and clinical symptoms tends to be more direct. The definition of instability in the spinal fractures is the topic of ongoing research. Although fractures are traditionally divided into stable and unstable, all spinal components contribute to stability. Damage to any spinal structure gives rise to some degree of instability which is not an "all or nothing" phenomenon.

Key words: thoracolumbar spine; biomechanics; instability

- Illetişim adresi: Doç. Dr. Mustafa Erkan İnanmaz, Sakarya Üniversitesi Eğitim Araştırma Hastanesi Merkez Kampüsü Ortopedi Kliniği, Adapazarı, Sakarya Tel: 0532 - 6812941 e-posta: erkaninanmaz@yahoo.com

- Geliș tarihi: 1 Kasım 2018 Kabul tarihi: 1 Kasım 2018 
ervikal, torakal ve lomber omurgaların segmental yapıları, biyomekanik özellikleri ve yetmezlik mekanizmaları arasındaki farklılık nedeniyle, yaralanma tipleri değişiklik gösterir. Omurga kırıklarının büyük bir bölümü de, anatomi ve biyomekanik özellikler nedeniyle, torakolomber bileşke bölgesinde görülür. Bu bölge, hareket aralığı kısıtlı ve göğüs kafesi tarafından desteklenmiş kifotik torakal omurga ile, daha hareketli lordotik lomber omurga arasındaki biyomekanik geçiş özelliğinden dolayı, travmayı oluşturan kuvvetlerin ilgi odağı haline gelmektedir. Bunun sonucunda, izole minör kompresyon yaralanmasından instabil çevresel osteoligamentöz yapıların yaralanmasına kadar, geniş bir yelpazede yaralanmalar meydana gelir.

Biyomekanik işleyiş ve kavramların açık bir şekilde anlaşılması ve yorumlanması, omurga travmalarının tedavi prensiplerinin temel öğelerini oluşturmaktadır. Omurga kırıklarının tedavisinin planlanmasında ilk basamak stabilitenin değerlendirilmesidir. Cerrahi tedavi yöntemleri ile bozulan spinal biyomekaniğin restorasyonu ve bunun sürdürülmesi ana hedeftir. ${ }^{[1,2]}$

\section{TRAVMATIK INSTABILITE}

White ve Panjabi, omurga stabilitesini "fizyolojik yüklere karşı koyabilme yetisi" olarak tanımlamakta ve buna göre, kişiyi ayağa kaldırmadan, yani fizyolojik yüklere karşı bırakmadan önce göz önüne alınması gerekenleri tanımlamaktadır. ${ }^{[3,4]}$ Amerikan Ortopedik Cerrahlar Derneği (AAOS) tarafindan yapılan benzer bir tanımlamada ise 'vertebranın tüm fizyolojik hareketlerde, birbirine bağlı ve normal deplasman sınırlarında kalması' olarak ifade edilmiştir. ${ }^{[5]}$

Kemik ve yumuşak dokuların spinal stabiliteye katkıları ve travmanın bu yapılar üzerindeki etkilerini analiz eden pek çok biyomekanik çalışma yapılmıştır. Holdsworth ve ark., spinal stabilite kavramını kolon teorisiyle açıklamaya çalıştılar. Vertebra cismi ve diskten oluşan, kompresif streslere dirençli anterior kolon ile tensil streslere maruz kalan ve nöral kavislerin de yer aldığı arka kolondan oluşan ikili kolon modelini önerdi. Holdsworth, posterior kolona "posterior bağ kompleksi" (PLC) tanımlamasını getirerek stabilite üzerindeki anahtar rolünden bahsetti. ${ }^{[6]}$ Sonrasında Denis, üç kolondan oluşturulan bir model önerdi. Bu modelde vertebra cisminin ve diskin ön yarısı ile anterior longitudinal bağdan (ALL) oluşan kısmına ön kolon, cismin ve diskin arka yarısı ve posterior longitudinal bağdan (PLL) oluşan kısmını ise orta kolon olmak üzere ikiye böldü (Şekil 1). Posterior kolon ise Holdsworth'un tanımlamasındaki gibi, nöral ark ve supraspinöz, interspinöz, ligamentum flavum ve faset eklem kapsülleri içeren PLC'den oluşmaktaydı. Orta kolonun spinal stabilitenin belirlenmesinde önemli bir rol oynadığını ve en az iki kolonun eş zamanlı yetmezlikleri sonrası instabilite geliştiğini bildirdi. Burst (patlama) kırıklarını hem anterior, hem de orta kolona verdiği eş zamanlı hasar nedeniyle, instabil kırıklar olarak yeniden tanımladı. Denis'in modeli, hem kemik hem de yumuşak dokuyu ilgilendiren omurga kırıkları sonrası gelişen instabiliteyi değerlendirmede kullanışlıdır ve bugün en çok kabul edilen referanslar arasındadır. Orta kolon ayrı anatomik bir yapı olmasa da, yürütülen histolojik ve biyomekanik çalışmalar bu bölgenin ayrı bir yapı olarak ele alınabileceğini göstermektedir. ${ }^{[4]}$ Üç kolon modelinde Denis, kırıkları orta kolonun durumuna göre ön kolon kırıkları çökme kırıkları, ön ve orta kolon kırıkları burst kırıkları, üç kolon kırıkları ise rotasyonel burst kırığı veya kırıklı çıkık olarak sınıflandırdı. ${ }^{[7]}$

Mc Afee ve ark., üç kolon teorisini desteklemişler, ancak orta kolonu daha küçük bir bölüm olarak PLL, omurga cismi $1 / 3$ posterioru ve anulus fibrosis $1 / 3$ posterioru olarak tanımlamışlardır. Orta kolon hasarı, arka kolon hasarı ile birlikte ise instabilite oluştuğunu ileri sürmüşlerdir. Burst kırıklarını stabil ve instabil olarak iki gruba ayırmışlardır.

1) Stabil burst kırı̆ı: Belirgin spinal deformite ve kanal darlığı yaratmayan, yalnızca ön ve arka kolonun tutulduğu burst kırıklarıdır. Bu tipte; arka kolon hasarı olsa bile, kırık laminospinöz bileşkede vertikal tarzda ayrışma şeklindedir ve arka bağ yapıları sağlamdır.

2) İnstabil burst kırı̆̆ı: Yüksek oranda nörolojik yaralanmanın eşlik ettiği ve hem kemiksel hem de bağ yönünden arka kolonun hasar gördügüü burst kırıklarıdır. ${ }^{[8]}$

Kostuik, instabiliteyi anatomik ve klinik olarak iki grupta incelemiştir. T2-T9 arası kırıkları çevresindeki toraks nedeniyle, torakolomber bölgeye göre daha stabil kabul etmiş, L4-L5 kırıklarını da daha geniş spinal kanala sahip olmaları nedeniyle stabil olarak değerlendirmiştir. ${ }^{[9]}$ Farcy ve Weidenbaum, Denis'in üç kolon modelini değiştirerek her üç kolondaki kemik ve yumuşak doku hasarını ayrı ayrı değerlendiren altı elemanlı bir sınıflandırma getirmişlerdir. Buna göre; her kolondaki kemik yapı B (bone) ile yumuşak dokular ise L (ligament) ile gösterilir. Böylece, bir omur ve diski kapsayan bir hareketli segment altı elemandan oluşur. Bu elemanların durumu manyetik rezonans (MR) görüntüleme ile tespit edilir. Üç ve üstünde elemanın hasarı instabiliteyi gösterir. Burst kırığı, genelde ön ve orta kolonların "B" ve "L"lerini kapsar ve bu yüzden dört elamanı tutar, instabildir 


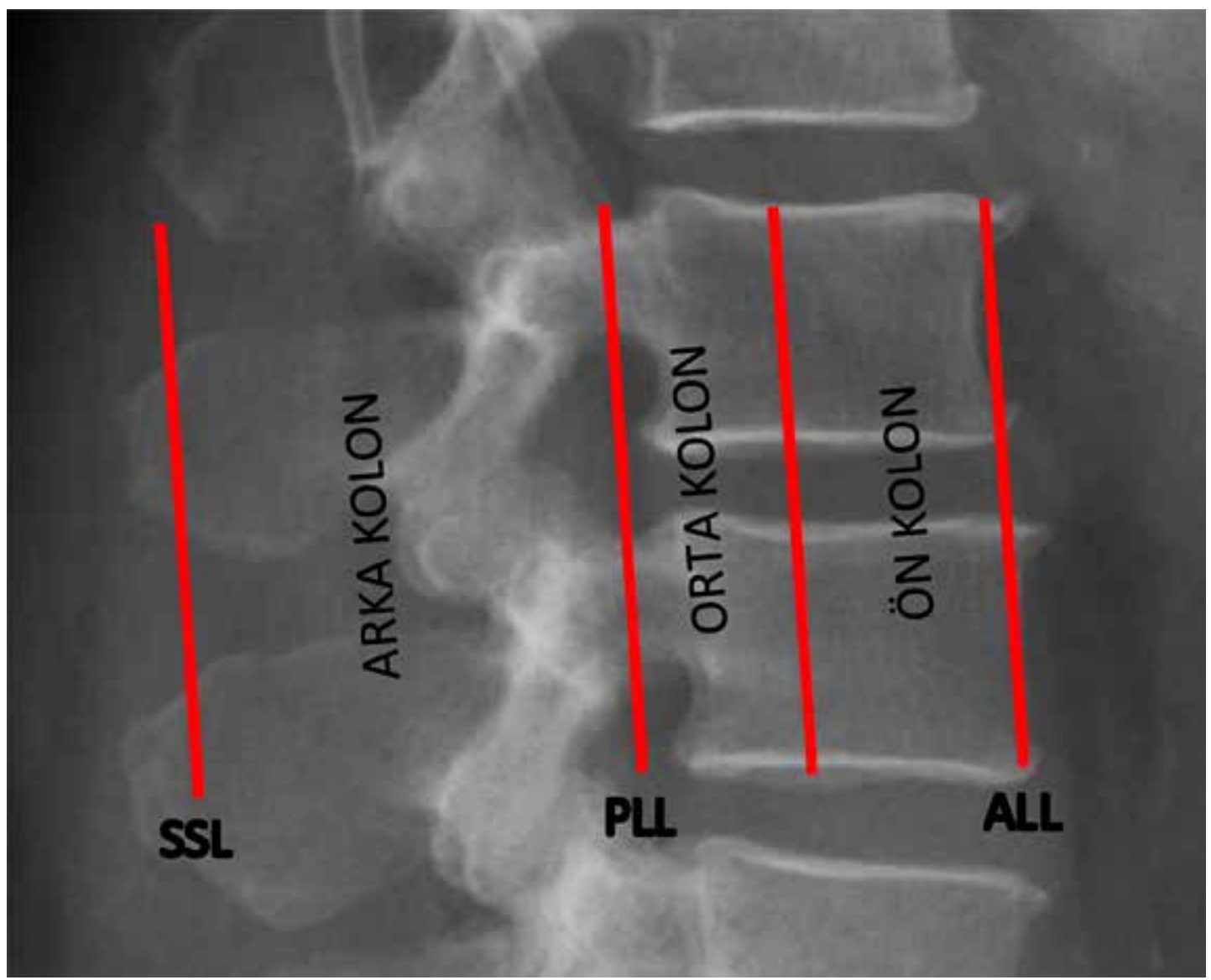

Şekil 1. Denis'in üç kolon modeli.

$(2 \mathrm{~B}+2 \mathrm{~L})$. Kompresyon kırığı ön kolonu $(\mathrm{B}+\mathrm{L})$, iki elemanı tutar, stabildir. Kırıklı-çıkıkta tüm kolon ve elemanlar hasarlanmıştır ve altı elemanı da tutan instabilite mevcuttur. ${ }^{[10]}$ Dunn, üç kolon teorisine göre orta kolonun sağlamlığını esas almış, şu görüşleri ileri sürmüştür:

1. T8 üzerindeki kırıklarda orta kolon hasarı olsa da toraks sağlam ise stabildir. Göğüs duvarı instabil ise omurga kırığı da instabildir.

2. L4 ve L5'te orta kolon hasarına rağmen arka elemanlar sağlam ve yalnız uzunlamasına kırık varsa stabildir.

3. Chance kırı̆̆ karşı taraftaki yumuşak doku yaralanmaları nedeni ile instabildir.

4. Kompresyon kırıklarında, omurga yükseklik kaybı $\% 50$ 'den fazla ise instabil kabul edilir.

5. Tüm kırıklı çıkıklar instabildir. ${ }^{[11]}$
Edwards ve Levine, bazı özel radyolojik bulgulara dayanarak instabilite kriterlerini bildirmişlerdir:

1. Lateral grafide omurga cismindeki kollaps ile anterior-posterior (AP) grafide pediküller arası mesafenin genişlemesi.

2. Tomografi kesitlerinde lomber bölgede kanal çapının $1 / 3$ 'den daha fazla daralmaya neden olan kırıklar.

3. Herhangi bir planda omurga cisimleri arasında 2,5 mm'den fazla kayma veya kırık olmaksızın spinöz çıkıntılarda veya faset eklemlerde belirgin kayma varlığı.

4. ìki taraflı faset eklem çıkığı.

5. Omur cisminin ön çökmesinin \%50'den fazla olduğu olgularda, spinöz çıkıntılar ve lamina arasında anormal açılanmanın varlığı instabiliteyi gösterir. ${ }^{[12,13]}$ 
Kifune ve ark., kadavra omurgasında yüksek hızlı travma aparatlarınca üretilmiş aksiyel ve kompresyon/ fleksiyon yüklerine cevabı değerlendirdikleri çalışmalarında, yüklenmeyle oluşan deplasman ve esneme hareketleri sonrası, hareket aralığını (ROM), nötr zon (NZ), elastik zon (EZ) instabilitelerini değerlendirmişler; sırasıyla 57, 84 ve $104 \mathrm{Nm}$ ortalama darbe enerjisi sonrası end-plate'lerde kama ve burst kırıklarını izlemişler; hareket modelleri üzerinde, end-plate kırıkları belirgin bir değişiklik oluşturmazken, ilk değişikliklerin kama kırıklarında meydana geldiğini belirtmişlerdir. Burst kırıkları, instabilite üzerinde en büyük değişiklikleri göstermiştir. Burst kırıklarının instabiliteye etkisi kama kırıkları ile karşılaştırıldığında, aralarında yüksek oranda farklılık olduğunu belirtmişlerdir. Omurda ilk lezyonu oluşturabilmek için önemli miktarda enerji gerekirken, bu enerjiye ek olarak uygulanacak nispeten küçük bir enerji, instabilite meydana getirmeye yeterlidir. Klinik bakış açısından, konservatif takip gerektiren stabil bir kırığı cerrahi stabilizasyon gerektiren instabil kırı̆ga dönüştürmek için, şiddeti sadece küçük bir miktarda artmış bir travma yeterlidir. ${ }^{[14]}$

Son yıllarda, özellikle genç hastalarda, cerrahi morbiditeyi azaltmak ve daha az sayıda hareketli segmenti füzyon alanına dahil etmek için uygulanan kısa segment enstrümantasyon sonrasında, yüksek oranda kifoz ve enstrümantasyon yetmezliği geliştiği izlenmiştir. ${ }^{[15]}$ McCormack ve ark., kırık hatlarının omurga gövdesine ve komşu diske uzanımını değerlendirerek, anterior spinal kolonun rezidüel yük taşıma kapasitesinin tahmin edilebileceğini ve bunun sonucunda konservatif ve cerrahi yaklaşım sonuçlarının, enstrümantasyon (kısa ve uzun segment) yetmezliği riskinin de tahmin edilebilir olduğunu iddia etmişlerdir. McCormack ve ark.'na göre, uzun kemik kırıklarındaki kemik ile implant arasında doğru yük dağılımını sağlayıp, pseudarthrosis ve implant başarısızlığını engelleyen osteosentez prensibi, akut spinal kırıklarının tedavi yönetiminde de geçerlidir. McCormack ve ark. tarafından, toplam puanın üç ile dokuz arasında değişkenlik gösterdiği, yük paylaşımı sınıflandırması (LSC) tanımlanmıştır. Bu skorlama, hasar görmüş vertebra gövdesi miktarı (bilgisayarlı tomografi [BT] sagittal rekonstrüksiyonunda), kırık parçalarının yatay dağılımı (aksiyel BT taramalarında) ve ameliyat sonrası anterior kolonda kifoz düzeltme derecesi temel alınarak yapılmıştır. Kırık parçalarının aşıı radyal deplasmanı, anterior kolonun yetersiz redüksiyonu halinde kifoz gelişiminin kaçınılmaz olduğunu ve mekanik stres altında anterior kolonun yük paylaşımı yeterince olmadığı için, bunun cerrahi başarısızlık için bir risk teşkil ettiğini belirtmişlerdir. Kısa segment posterior tespit uygulanan veya konservatif takip edilen yüksek skorlu hastalarda, kifoz gelişimi ve enstrümantasyon yetmezliği meydana gelme eğilimindedir. Bunun yanı sıra, düşük skorlu hastaların, uzun segment enstrümantasyon uygulaması ile gereksiz morbiditeye maruz kalabileceklerini bildirmişlerdir. ${ }^{16]}$

McCormack sınıflandırması, redüksiyon kaybına yol açabilecek kırıkları saptamak için etkilidir, fakat omurga stabilitesinin korunmasında başlıca etmen olan bağların bütünlüklerinin bozulmasını hesaba katmaz. Son yıllarda yapılan çalışmalarda, posterior bağ yetmezliğinin geçmişte tahmin edilenden çok daha yaygın olduğu gösterilmiştir. Bir çalışmada, artmış interspinöz boşluk, $20^{\circ}$ üzeri lokal kifoz, sagittal deplasman, $\% 50$ 'nin üzerinde bir yükseklik kaybı ve faset kırıkları, mekanik instabilitenin radyolojik özellikleri olarak öne sürülmüştür. Bununla birlikte, bu bulgular olmayıp, PLC yaralanması durumunda olan kırıklar da instabil olabilir. ${ }^{[15]}$ Konservatif olarak tedavi edilen hastalarda gözden kaçırılmış bağ ve disk lezyonları, instabilite ve nörolojik hasarın yanı sıra, tekrarlayıcı kifoz ve kronik ağrıya veya cerrahi başarısızlığa neden olabilir.

Magerl'in torakolomber kırık sınıflandırması, artan instabilite derecesine karşılık gelen $A, B$ ve $C$ tipleri olarak adlandırılan üç ana grup kırı̆g içerir. Daha stabil olan Magerl A'yı (kompresyon) Magerl B (distraksiyon) tip kırıklardan ayırt eden önemli bulgu, posterior bağların durumudur. ${ }^{[17]}$ Yaralanma sonrası posterior bağların durumu, kırık omurga stabilitesi için büyük önem taşımaktadır. Burst kırıklarında instabilitenin değerlendirilmesinde, Denis'in yaklaşımında önemli bir bileşen olan orta sütundan ziyade, posterior kolonun durumunun daha iyi bir gösterge olduğunu ileri süren çalışmalar son yıllarda artmaktadır. ${ }^{[18]}$ Bu bağlardaki lezyona tanı konmaması ya da yanlış tedavi uygulandığı durumlarda, biyomekanik restorasyonun sağlanamaması nedeni ile progresif deformite, kronik ağrı ve kalıcı sakatlık gibi komplikasyonlar görülebilmektedir. Leferink ve ark., Tip A ve Tip B omurga kırıklı 160 hastanın ameliyat sırasında kayıtları ile görüntüleme kayıtlarının karşılaştıııldığı geriye dönük bir çalışmada, Tip B'ye ait kırıkların yaklaşık \%30'unun bağ lezyonlarının sıklıkla düz grafiler ve BT tetkiklerince teşhis edilememesi nedeniyle Tip A olarak sınıflandırıldığını bildirmişlerdir. ${ }^{[19]}$ Spinöz prosesler arasındaki mesafe ölçümü, distraksiyonun redükte olması durumunda yanıltıcı olabilir. Posterior bağların durumu, uygun bir tedavi stratejisi belirlemek için çok önemlidir. MR, bağlardaki değişiklikleri rutin olarak değerlendiren tek görüntüleme yöntemidir. Lee ve ark., MR'nin interspinöz, supraspinöz ve flavum bağlarındaki lezyonları saptamada doğruluk oranını sırasıyla $\% 97, \% 90,9$ ve $\% 87,9$ olarak bildirmişler ve yağ baskılanmış T2 ağırıklı sagittal sekansların rutin kullanımını önermektedirler. ${ }^{[20]}$ 
Burst kırıkları, anterior ve orta kolonun yetmezliği ile karakterizedir. Bu kırıklara yönelik cerrahi yaklaşımlar anterior, posterior veya kombine olabilir. Bu kırık tiplerinde yapılan cerrahi müdahaleler sonrasında kifotik deformite gelişmemesi her zaman garanti edilemez. Burst kırığından sonra ilerleyen kifozu önlemek için altın standart bir tedavi halen mevcut değildir. Kifoz, kalıcı okkült instabilitenin etkisiyle meydana gelmiş olan fizyolojik stres altında yavaş yavaş ortaya çıkar. Bu süreçte, spinal dizilim kaybı ve komşu yapıların kompansatuvar yanıtları ile ilişkili semptomlar baş gösterir. Daffner ve ark., posterior vertebral cismin kortikal hattının bozulmasının, orta kolondaki bir lezyonun öngörülmesinde bir işaret olduğunu belirtmiştir.[21] Ballock ve ark., hafif vertebral cisim kompresyonu ve deformasyonu durumunda bile BT gerekliliğini savunmuştur. ${ }^{[22]}$ Nitekim, karşılaştırmalı bir çalışmada, tüm instabil torakolomber kırıklarının üçte ikisi kadarı konvansiyonel radyografilerle gözden kaçırılmışken, BT ile duyarlılığın \%97,2'ye çıktığı görülmüştür. ${ }^{[23]}$ Nihai sonucu değerlendirmek için kullanılan farklı parametreler (radyolojik, klinik ve fonksiyonel) nedeniyle bu kırıkların ideal tedavisi konusundaki tartışmalar devam etmektedir.

İdeal spinal dizilim, kişi ayakta dururken minimum kas enerji harcamasına olanak sağlar. Normalde bu durum vertebranın fizyolojik eğimleri, pelvis morfolojisi, aksiyel ve appendiküler iskelet kasları arasındaki kompleks ilişki ile sağlanır. Debousset'nin ekonomi konisi kavramı, spino-pelvik dengenin dik bir postür sağlama, yürüme ve dik durma sırasında enerji harcamasını minimize etmesinin önemini ortaya koyar. ${ }^{[24]}$ Global spinal dengeyi koruma yaklaşımı, omurga travmaları sonrası izlenecek tedavi yöntemlerinin hedefi olan biyomekanik restorasyonun sağlanmasında ana unsurlardan biridir. Sagittal spinal eğrilikler, vertikal yüklere karşı, direnci 17 kata kadar arttırmaktadır. Bunu, deformasyonları daha önceden belirlenmiş ve paravertebral kas kontraksiyonu ile hızlıca kontrol edilebilen alanlara yönlendirerek sağlar. Omurganın fizyolojik eğrilikleri, travmatik güçlere verilen yanıtı etkiler. Torakal bölgede bulunan vertebra, kifozdan dolayı vücudun AP denge ekseninden uzaktır (dış odituvar kanallardan geçen, C7-T1 ve L5-S1 aralığında olan femoral başların merkezi) ve eksentrik kuvvetlerle karşı karşıya kalır. Dorsal kifoz, doğumda mevcut olan tek sagittal spinal eğriliktir. Servikal ve lomber lordozlar sırasıyla, yürüme sonrasında gelişsim gösterir. Hem normal bireylerde, hem de patolojik koşullarda sagittal omurga eğrileri, pelvik insidans (PI), sakral eğim (SS) ve pelvik tilt (PT) gibi farklı parametrelerce sınırları çizilmiş, pelvik geometrik değerlerce düzenlenir. ${ }^{[25,26]}$

\section{KAYNAKLAR}

1. Izzo R, Guarnieri G, Guglielmi G, Muto M. Biomechanics of the spine Part 1: Spinal stability. EurJ Radiol 2013;82(1):11826. Crossref

2. Izzo R, Guarnieri G, Guglielmi G, Muto M. Biomechanics of the spine Part 2: Spinal stability. Eur J Radiol 2013;82(1):12738. Crossref

3. White AA, Panjabi MM. The basic kinematics of the human spine. Spine 1978;3(1):12-20. Crossref

4. Berk H. Sirt-Bel Omur Kırıkları. TOTBID Derg 2008;7(1-2):20-34.

5. Kirkaldy-Willis WH. Presidential symposium on instability of the lumbar spine. Spine 1985;10(3):254. Crossref

6. Holdsworth FW. Fracture, dislocation and fracturedislocation of the spine. J Bone Joint Surg Br 1963;45B:6-20.

7. Denis $F$. The three columns spine and its significance in the classification of acute thoracolumbar spinal injuries. Spine 1983;8(8):817-31. Crossref

8. McAfee PC, Yuan HA, Frederickson BE, Lubicky JP. The Value of Computed Tomography in Thoracolumbar Fractures. J Bone Joint Surg 1983;65(4):461-73. Crossref

9. Kostuik JP. Anterior Fixation for Fractures of the Thoracic and Lumbar Spine with or without Neurologic Involvement. Clin Orthop Relat Res 1984;(189):103-15. Crossref

10. Farcy JP, Weidenbaum M, Glassman SD. Sagittal Index in Management of Thoracolumbar Burst Fractures. Spine 1990;15(9):958-65. Crossref

11. Dunn HK. Anterior Spine Stabilization and Decompression for Thoracolumbar Injuries. Orthop Clin North Am 1986;17(1):113-9.

12. Edwards CC, Lewine AM. Early rod-sleeve stabilization of the injured thoracic and lumbar spine. Orthop Clin North Am 1986;17(1):121-45..

13. Yetiş M. Torakolomber burst kırıklarında posterior enstrümantasyon ve füzyon sonuçlarımız. Tıpta Uzmanlık Tezi. İstanbul; 2009. p.34-7.

14. Kifune M, Panjabi MM, Arand M, Liu W. Fracture pattern and instability of thoracolumbar injuries. Eur Spine J 1995;4(2):98-103. Crossref

15. Knop C, Bastian L, Lange U, Oeser M, Zdichavsky M, Blauth $\mathrm{M}$. Complications in surgical treatment of thoracolumbar injuries. Eur Spine J 2002;11(3):214-26. Crossref

16. McCormack T, Karaikovic E, Gaines RW. The load sharing classification of spine fractures. Spine 1994;19(15):1741-4. Crossref

17. Magerl F, Aebi M, Gertzbein SD, Harms J, Nazarian S. A comprehensive classification of thoracic and lumbar injuries. Eur Spine J 1994;3(4):184-201. Crossref

18. James KS, Wenger KH, Schlegel JD, Dunn HK. Biomechanical evaluation of the stability of thoracolumbar burst fractures. Spine 1994;19(15):1731-40. Crossref

19. Leferink VJM, Veldhuis EFM, Zimmerman KW, ten Vergert $E$, ten Duis $H$. Classificational problems in ligamentary distraction type vertebral fractures: $30 \%$ of all B-type fractures are initially unrecognised. Eur Spine J 2002;11(3):246-50. Crossref

20. Lee HM, Kim HS, Kim DJ, Suk KS, ParkJO, Kim NH. Reliability of magnetic resonance imaging in detecting posterior ligament complex injury in thoracolumbar spinal fractures. Spine 2000;25(16):2079-84. Crossref 
21. Daffner RH, Deeb ZL, Rothfus WE. The posterior vertebral body line: importance in the prediction of burst fractures. AJR Am J Roentgenol 1987;148(1):93-6. Crossref

22. Ballock RT, Mackersie R, Abitbol JJ, Cervilla V, Resnick $D$, Garfin. Can burst fractures be predicted from plain radiographs? J Bone Joint Surg Br 1992;74-B(1):147-50. Crossref

23. Wintermark M, Mouhsine E, Theurmann N, Mordasini P, Melle G, Leyvraz PF, Schnyder P. Thoracolumbar spine fractures in patients who have sustained severe trauma: depiction with multi-detector row CT. Radiology 2003;227(3):681-9. Crossref
24. , Schwab F, Patel A, Ungar B, Farcy JP, Lafage V. Adult spinal deformity-postoperative standing imbalance: how much can you tolerate? An overview of key parameters in 35 assessing alignment and planning corrective surgery. Spine 2010;35(25):2224-31. Crossref

25. Morvan G, Wybier M, Mathieu P, Vuillemin V, Guerini H. Plain radiographs of the spine: static and relationships between spine and pelvis. J Radiol 2008;89(5 Pt 2):654-63.

26. Vialle R, Levassor N, Rillardon L, Templier A, Skalli W, Guigui P. Radiographic analysis of the sagittal alignment and balance of the spine in asymptomatic subjects. J Bone Joint Surg 2005;87(2):260-7. Crossref 